\title{
J
}

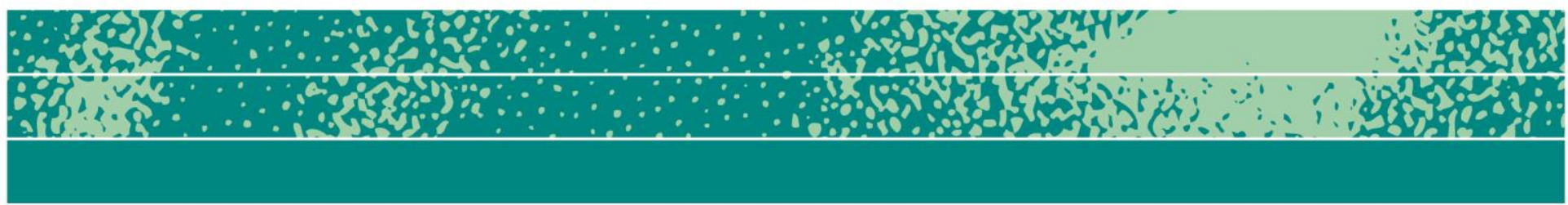

\section{No Family Company Without Family: The Professionalization of a Chinese Family Business in Hong Kong}

Karin Ling-Fung Chau and Heung Wah Wong

This paper has two objectives. First, it attempts to examine the logic underpinning the dominant paradigm in the study of professionalisation of family businesses and identifies its major limitations. Secondly, using a case study of a Chinese family business in Hong Kong through crises and prosperous times, it proposes an alternative framework that sees professionalisation as a complex, context-specific social process shaped by the specific cultural form of family together with market developments, individual characteristics of the owning families and owners, and the micro politics within family firms, the consequences of which are always very complex. Professionalisation is by no means a guaranteed, linear process; for example, as the following case study shows, there is always a possibility for a company to revert to the previous mode of management even after professional management is introduced and well established, when circumstances have changed. Moreover, unlike most family business literature, our study is ethnographic in character and draws upon anthropological insights which enable us to identify issues that are invariably neglected in other studies in the field.

Page 1 of 21

JBA 10(2): 262-282 Fall 2021

(C) The Author(s) 2021 ISSN 2245-4217

www.cbs.dk/jba

10.22439/jba.v10i2.6 413 
The paper is organised into four sections. In the first section, we review the two main approaches to professionalisation of family businesses to identify their underlying logic, assumptions, and limitations. In the second section, we present a case study of professionalisation of a Chinese family business in Hong Kong making use of Victor Turner's notion of social drama. We will then discuss how the case study demonstrates the role of the specific cultural form of the Chinese family in shaping the course of professionalisation and how the process played out in the power politics of different individual actors. Our conclusion spells out the theoretical, methodological, and practical implications of the paper.

\section{Studying Professionalisation of Family Businesses: A Critical Review}

In the last two decades, attempts have been made to clarify and reassess the concept of professionalisation within family business studies (e.g. Songini 2006; Hall and Nordqvist 2008; Stewart and Hitt 2012; Dekker et al 2013,2015). There is no consensus as to what professionalisation entails in the context of a family business (Stewart and Hitt 2012). Julie Dekker et al (2015: 517-518) argue that there is a wide gap between the research that pays attention to the theoretical underpinning of professionalisation and empirical studies that 'operationalize the concept in an oversimplified manner'. In this section, we examine the narrow understanding of professionalisation and its extended version that dominate the field. We will demonstrate how both approaches are informed by the emphasis on Weberian rationality and its universal applicability and superiority.

\section{Traditional Approach}

The traditional approach to professionalisation of family businesses focuses on the recruitment of nonfamily professional managers to replace family managers (e.g., Berenbeim 1990; Chittoor and Das 2007; Lin and Hu 2007; Zhang and Ma 2009). Professionalisation is thus primarily seen as a process that diminishes family influence by the increasing introduction of professional managers who 'save the business' by breaking up the family's hold over it. Alex Stewart and Michael A. Hitt (2012), for example, argue that this understanding is predicated upon and reinforced by sets of dichotomies differentiating family businesses from nonfamily businesses that in turn produce stereotypical views of family and nonfamily businesses. These stereotypes reinforce the idea that family businesses fare worse than nonfamily businesses and therefore require professionalisation (Stewart and Hitt 2012: 59).

The recruitment of professional managers is generally argued to be the main way of making a family business more like a nonfamily 
business. Replacing family managers with nonfamily managers should be the focal point of professionalisation (e.g., Chittoor and Das, 2007; Lin and $\mathrm{Hu}$ 2007). Several studies have pointed out how family management and professional management are generally regarded as mutually exclusive and more importantly how the former is considered inferior to the latter (Hall and Nordqvist 2008; Dekker et al 2013, 2015; Salvato et al 2012). The status of family managers as 'insiders' is ascribed to their personal, emotional and specific ties to the family (Dyer 1989: 221), while professional managers as 'outsiders' are considered to acquire their status through formal management education and technical qualifications accomplishment (Dyer 1989: 221) and the ability to adhere to and put into practice the managerial ethics that they acquired in school in different organisational contexts (Hall and Nordqvist 2008: 54). Family management thus represents a subjective, personal, and emotional approach, while professional management represents a 'non contextual and objective, impersonal, and non-emotional approach to the job' (Hall and Nordqvist 2008: 54).

This traditional understanding of professional management, as Annika Hall and Mattias Nordqvist (2008: 53) argue, is rooted in the Weberian notion of bureaucratic organisation 'based on objective rules, norms, and rational decision making, where managers' authority is grounded in technical qualifications and rational values rather than in individual characteristics and personal ownership rights.' The Weberian notion of bureaucratic organisation differentiates modern organisations characterised by rational and legal authority from organisations relying on charismatic and traditional authority. This Weberian association of efficiency and rationality with modernity, to further develop Hall and Nordqvist (2008)'s argument, contributes to the dominant, antithetical view of family norms and professional norms in the study of professionalisation of family businesses. The former is stereotypically characterised by paternalism, subjectivity and irregularity (e.g. Johannisson and Huse 2000; Fang et al 2012), and the latter by managerialism that emphasises formalised mechanisms of control (Johannisson and Huse 2000). Through the proliferation of management schools, "the managerial mode is established as the "normal" way of organizing economic activity' (Johannisson and Huse 2000: 357).

The belief in the superiority of Weberian rationality, underpinning modern management training, explains why W. Gibb Dyer (1986: 101) saw professionalisation as 'a rational alternative to nepotism and familial conflicts that plague a family business', a view widely shared in the field of family business studies. The goal of professionalisation is thus perceived to 'provide objectivity and rationality to an emotional milieu' (Upton and Heck 1997: 252 cited in Hall and Nordqvist 2008: 53) by introducing formal governance mechanisms, organisational structure, formal strategic planning and control systems, and involvement of 
nonfamily members in boards and management (Songini 2006: 270) to family firms. In a nutshell, this traditional approach argues that successful professionalisation is about making a family business look like a nonfamily business. It is evidenced by the removal of family members from day-to-day management and the formalisation of management processes.

\section{Revisionist Approach}

This traditional approach to professionalisation of family firms has been challenged by what we call a 'revisionist' approach that mainly focuses on dismantling the dichotomisation between family and professional management and argues for an extended conceptualisation of professionalisation (e.g., Dekker et al 2013, 2015; Polat 2020; Stewart and Hitt 2012). The revisionist approach emphasises that through training, family members can also become professional managers and thus management by family members should not be regarded as antithetical to professional management (e.g., Dyer 1986; Dekker et al 2013, 2015; Hall and Nordqvist 2008). Central to the revisionist approach is the view that professionalisation should not be perceived as a one-dimensional construct solely determined by the replacement of family managers with external nonfamily managers (e.g., Stewart and Hitt 2012; Dekker et al $2013,2015)$. Attributing the inconsistency in previous research on the relationship between professionalisation and performance to the adoption of a narrow understanding of the concept, Dekker et al (2015), for instance, propose a multi-dimensional framework consisting of five dimensions: financial control systems, nonfamily involvement in governance systems, human resource control systems, decentralisation of authority and top-level activeness. Stewart and Hitt (2012) also identify six different modes of professionalisation by family businesses ${ }^{1}$.

We have to stress immediately that the revisionist approach, with its emphasis on the diversity of professionalisation, does not challenge the inevitability and desirability of professionalisation as a rationalisation process whereby, as stated by Dekker et al (2015: 516), a family business is transformed into 'a more formalized, structured, and institutionalized corporation'. Both traditional and revisionist approaches see professionalisation as a natural point in a family business's life cycle and as an inevitable part of its evolutionary process towards continuity and vitality (e.g Dyer 1989: 233-4; Giovannoni et al 2011: 129). The main difference between the two is just how: the former focuses on a single aspect, while the latter draws our attention to a range of possible dimensions. Similarly, both approaches espouse the separation of family

\footnotetext{
${ }^{1}$ The six modes identified by Stewart and Hitt (2012) are: minimally professional family firms, wealth-dispensing private family firms, entrepreneurially operated family firms, entrepreneurial family business groups, pseudoprofessional public family firms and hybrid professional family firms.
} 
and business: the traditional approach focuses on the retreat of family involvement from management while the revisionist approach sees the potentiality of rationalising family norms through different means. That is why we call the revisionist approach 'revisionist' as it does not challenge the fundamental logic of professionalising company management.

\section{Professionalisation and Family as Culturally Universal?}

The major problem with the two dominant approaches to professionalisation within the family business research by management scientists is that they presuppose some theoretical assumptions a priori that the family system is differentiated from the business system and that the family is confined to the domestic sphere of the society, while the business system and its managerial ideology are characterised by efficiency and rationality. Their acceptance of Weberian association of efficiency and rationality with modernity further adds an evolutionary nuance to the process that makes people think that the transition from family business management to professional management is inevitable and unidirectional. These theoretical assumptions, however, simply cannot stand the empirical challenges in most cultural contexts including the European experiences. Family firms in Italy, for example, are heavily shaped by the specific cultural form of Italian families (Yanagisako 2002). As the case study below shows, Chinese families and businesses in Hong Kong are ordered by a single system of relationships known by anthropologists as 'kinship'. Chinese entrepreneurs manage their businesses in a way that replicates Chinese family life. Thus, father and son, brother and brother, and husband and wife are the main relations in Chinese family businesses. Understanding Chinese family businesses therefore requires us not to consider family and business as two separate systems that mutually shape each other, but rather to focus on the fact that a Chinese family business is constituted, organised, and operated as a Chinese family.

'Chinese' is italicised to emphasise that there is a particular nature to the Chinese family. Family as a social institution cannot be assumed to be the same cross-culturally. Unfortunately, almost no attempt is seen in the literature on professionalisation of family business to examine the specificity of family in different cultural contexts. The lack of attention in the literature to the cultural specificity of family is surprising given the fact that family influence is seen as the key determinant distinguishing family businesses from nonfamily businesses in the existing literature. Stewart and Hitt (2012: 65) observe the tendency of the research to neglect the 'familial domain'. They point out specifically that kinship, for instance, has not been studied as a key independent variable (Stewart and Hitt 2012: 65). Hall and Nordqvist (2008), meanwhile, treat family culture as a core element, and yet only emphasise the influence of individual 
families on corporate culture. Critically, these approaches fail to treat the concept of family as culturally specific, and or to recognise that the nature of family shapes the professionalisation of family businesses in different ways in different cultural contexts. We argue that different cultures have different ideas of family which further shape the management and professionalisation of family businesses. In fact, it is well recognised that the management of Chinese family businesses is distinctive from that of Western and Japanese family businesses (Tsui-Auch 2004: 695).

The failure of the literature to situate professionalisation of family firms in a specific cultural context, as Hall and Nordqvist (2008: 55) point out, produces a static and abstract view of professionalisation. The ahistorical, asocial, and acultural view of professionalisation is further reinforced by the methodological bias that favours quantitative over qualitative research (Johannisson and Huse 2000: 361). Such a methodological bias explains why the majority of literature fails to acknowledge, emphasise, and study the processual nature of professionalisation. The dominant view in the literature assumes that professionalisation is either an event in which a group of professional managers attempt to replace a group of family managers, or, if the analysis is more sophisticated, as a result of the configuration of a list of variables at different levels. The inadequacy of the existing literature stems from the fact that it largely ignores such pressing questions as: What is the meaning of family in the specific cultural context in which the family firm concerned locates? Who are the professional managers and family managers? What are their motivations, goals, and expectations? How do they interact with each other and how do the power politics of their interactions affect the process and outcome of professionalisation?

In light of the above limitations, we propose an alternative framework to study the professionalisation of family businesses which puts the culturally specific meaning of family as the central analytical focus and see how the specific cultural meaning of family shapes the way professionalisation unfolds itself. The framework also enables us to perceive professionalisation as a social process enacted through the power politics among individual actors. This framework is predicated upon the view that families take on different cultural forms; that different cultural forms of family in turn lead to different cultural forms of family businesses; and that the process of professionalisation takes place in a specific context in which individual actors interact with each other. We propose that Victor Turner's concept of 'social drama' can be adopted to capture the complex dynamics of the process of professionalisation. As Turner (1987[1984]: 33) points out, social drama '[takes] place in what Kurt Lewin might have called 'aharmonic' phases of ongoing process. When the interests and attitudes of groups and individuals stood in obvious opposition, social dramas did seem to me to constitute isolable and minutely describable units of social process'. Our adoption of the 
concept of 'social drama' in analysing the process of professionalisation is to highlight the different agendas, motivations, and goals of different major players involved in the process according to which each major player acts of his or her own volition upon specific circumstances and interactions that are never static. We will illustrate, through the case study of the professionalisation of a Chinese family business in Hong Kong, not only how the Chinese family culture shaped the management of the Chinese family business and the course of its professionalisation, but also the complexity involved.

\section{Case Study ${ }^{2}$}

Fong Bou Lung Jewellery Limited (FBL) was founded in 1971 by Fong Bou Lung $^{3}$, after whom the company is named. A man of humble origins, Fong was born in Hong Kong in 1936 and received only two years of formal education. He was sent to a goldsmith to work as an apprentice at the age of 13 to support his family. Around 1960, he set up his own workshop to manufacture jewellery for local retailers and trading houses. By the end of the 1960s, Fong had already made a name in the local jewellery manufacturing sector and decided to incorporate his business in 1971. Fong then ventured into export and showroom businesses catering to overseas clients and tourists visiting Hong Kong. In 1977, Fong opened his first jewellery retail store in a high-end shopping mall in Hong Kong, transforming his company from a manufacturer to a retail brand. The company was listed on the Hong Kong Exchange in 1987. Within three decades, Fong had developed a one-man workshop into one of the largest jewellery retailers in Hong Kong with retail outlets and showrooms spanning mainland China, Taiwan, Malaysia, and Singapore. Fong Bou Lung, referring to both the company and the founder, became a household name in Hong Kong.

\section{FBL Is the Fong Family}

FBL was organised and managed according to the cultural logic of jia (family). ${ }^{4}$ First, the Fong family is the major shareholder of FBL (controlling around $72 \%$ of shares). Members of the Fong family also play an active and dominant role in its management. Fong had been the only

\footnotetext{
${ }^{2}$ The case study is based on the ethnographic research conducted on the company from 2013 to 2018. One of the authors conducted participant observations in the company from 2013 to 2014. We have also conducted indepth interviews with more than 30 members of the company. Part of the case study has been adapted from Wong and Chau (2020a; 2020b)

${ }^{3}$ To protect the identity of our informants, pseudonyms have been used.

${ }^{4}$ For a detailed discussion of the concept of jia, refer to Wong's paper in this special issue.
} 
leader in the company until he was forced to step down in 2000. Fong's brother and sister had both worked in Fong's workshop until the former emigrated to Canada and the latter married. Fong's wife was in charge of the company's bookkeeping. Two of Fong's three children, Daisy and Jackson, were appointed executive directors of the company, in 1993 and 1994 respectively ${ }^{5}$. Daisy oversaw FBL's operation in China while Jackson was in charge of the retail business in Hong Kong. Daisy stepped down from the board of directors in 2000 after the Asian financial crisis and became a housewife. Jackson stayed and succeeded Fong as the company's chairman until he and his father were arrested and imprisoned in the early 2010s. Emma, Jackson's wife, took over the chairmanship and started to recruit a number of professional managers from outside in 2011 to help reform and rebrand the company. Jackson re-joined the company in 2011 as Chief Merchandising Officer, a role redefined as Deputy CEO since 2013.

The organisation of FBL mirrored that of jia in two important ways. First, it was organised around a series of concentric circles of social relations with Fong, the jiazhang (head of a jia), as the power centre. The status of an employee in the FBL depended on his/her closeness with Fong. While family-employees (fang/jia-zu ${ }^{6}$ members) were, by default, the closest to Fong, non-family employees, especially the long-serving employees (the dependent members of Fong's jia) also enjoyed a special status in the company because of their loyalty to Fong. Long-serving employees were regarded as the elders in the family business as if they were the 'real' kin. The fictive 'kinship' principle can be reflected in the way employees were addressed in kinship terms like shu (uncle), ge (elder brother), jie (elder sister) and mei (younger sister) in the company. However, we have to stress that these long-serving employees are never able to become the member of Fong's family as Chinese kinship, as Wong argues in his paper, is genealogically constituted and can never be made performatively.

Secondly, the organisation of FBL was maintained through mutual commitment between Fong and the employees. Wong argues in his paper in this special issue that jia is a joint account from which the jiazhang allocates the financial resources to the members according to their needs and, in return, every member of the jia should contributes financially to the joint account through the jiazhang. Fong as the jiazhang of FBL likewise had the moral responsibility to take care of the welfare of the

\footnotetext{
${ }^{5}$ Fong's eldest son, Joseph, has never participated in the family business. According to Fong, Joseph has never been interested in running it. Fong could do nothing to prevent his eldest son pursuing his own interest, which is not common in the Chinese context.

${ }^{6}$ For a detailed discussion of the concept of fang/jia-zu, refer to Wong's paper in this special issue.
} 
employees. He repeatedly emphasised that his major concern was to guarantee the livelihood of the employees. In return, employees were expected to demonstrate their loyalty and commitment to Fong by advancing and putting the interests of Fong and his family over those of others. The stronger the personal dedication an employee showed, the more committed Fong would be to safeguard his/her welfare even beyond the workplace. In effect, the employees did not serve the company but Fong, and by extension, Fong's jia-zu. Among the employees, Fong was nicknamed aye (master of the household), Jackson shaoye (young master of the household) and Emma shaonai (the wife of the young master of the household).

Three managerial features can be identified in the organisation of FBL: (1) Fong's absolute power in the company, (2) disregard of the organisational chart, and (3) the formation of holistic relationships. Fong had absolute power over everything of the company as he saw himself and was seen by others as the jiazhang of the company. Fong, for example, did not assign work according to the formal positions of the employees but their relationships with him. Thus, while a formal organisation chart existed, it was largely ignored. The emphasis on the mutual commitment between Fong and employees also led to the blurring of the boundary between the public (work) and private (personal) lives, and the integration of different categories of relationships - colleague, comrade, friend, kinship - through the reciprocal exchange of $l i$ (rites). The company encouraged breaking down the formal barriers between one's work and non-work life.

As FBL grew in scale, and especially after it went public, the problem with Fong's management became more salient. As Fong ran the company as his own jia, he was surrounded by employees who were accountable only to him. Consequently, corporate governance was limited and weak, and the operation of the company became increasingly inefficient. These problems eventually led to a series of crises that threatened the control of the Fong family over the company, ushering in reforms and professionalisation.

\section{The Professionalisatoin of FBL}

The professionalisation of FBL can be seen as a social process in which the Fong family responded to the challenges posed to its management and dominance of the company. In the sections that follow, we analyse the social process through Turner's concept of social drama which consists of four stages: breach, crisis, redressive action and reintegration or schism. We shall illustrate the dynamics of the professionalisation process stage by stage. 


\section{The Breach: Asian Financial Crisis}

The breach set in when the company was hard hit by the 1997 Asian financial crisis and Fong went bankrupt. To ensure that FBL would not fall into the hands of outsiders, Jackson replaced Fong to become the chairman of the company. It took Jackson four years to put the company back on track. In 2004, a debt restructuring proposal was passed in the annual general meeting. Jackson also redeemed Fong's shares, making himself the controlling shareholder of FBL, and securing the dominant position of the Fong family in the company. Fong also revoked the bankruptcy order after reaching agreements with his creditors.

Before the financial crisis, Fong had never thought about any succession plan, and he still attempted to lead the company after stepping down as chairman. However, Jackson, as the new head of the company, was eager to introduce changes to the company according to his own vision. Jackson aspired to transform FBL from a traditional Chinese goldsmith into an international brand, like Tiffany and Cartier, which, Jackson believed, would differentiate FBL from its competitors. Jackson's effort to 'modernise' FBL can also be seen as an attempt to differentiate himself from his father, who could not be bothered to think and talk about brand image and value. Jackson's reform however did not touch upon the management and governance of the company as a jia, which had dragged the company into financial crisis in the first place.

\section{The Crisis: The Court Case}

When the Fong family thought that the financial crisis was over, Fong, Jackson and three other senior managers of FBL were prosecuted by the Independent Commission Against Corruption (ICAC) ${ }^{7}$ in 2006. They were charged with bribery, false accounting, embezzlement and defrauding the Inland Revenue Department (IRD). Most of the charges were related to the illegal commission system devised to foster FBL's showroom business, which relied on the help of travel agents ${ }^{8}$. Fong and Jackson were also charged with stealing money from the company through the commission system and disguised staff bonus.

Fong was still furious (when interviewed for this article) when asked about the court case. He found the whole idea of stealing money from his own company ridiculous. For him, it was as if he were being

\footnotetext{
${ }^{7}$ The ICAC is a special agency established by the Hong Kong government in 1974 to curb corruption.

${ }^{8}$ According to the published judicial documents, in order to attract more tourists to visit the showrooms, the company paid extra commissions to the employees of tour operators and agents without the consent or acknowledgement of their employers. To disguise those transactions, the company set up bogus companies and created false accounting records.
} 
accused of taking money from his own piggy bank. Nevertheless, it does seem that Fong was not sufficiently clear about the concept of a public company. Thus, when asked about the motivation to list the company, he answered:

My friends told me that if my company was listed on the stock market, it's easier to raise funds and to expand. One dollar could be easily turned into ten dollars. So, I set [to float] as my target and I finally achieved the goal. I didn't know much about the procedure. I just found some people to help me with this.

It seems to us that Fong did not bother to distinguish between the public and the private, thus he continued to operate the listed company in the same way as he ran his jia.

In 2008, all of the defendants of the case were sentenced: Fong received a sentence of 3 years and 3 months and Jackson 5 years, which was the longest sentence among the convicted. Before the sentence, the Fong family had arranged for Emma to take over the chairmanship of the company to protect its family business.

\section{Redressive Action: Professionalisation}

When Emma became the chairwoman of the company, most senior executives had already left the company as a result of the court case and Emma desperately needed help in running the company. She was assisted by Desmond Chen, a family friend, who took up the position of CEO of the company. ${ }^{9}$ The most urgent tasks for Emma and Desmond were to convince the authorities to resume the trading of FBL shares on the Hong Kong Stock Exchange and rebuild the company's reputation. In 2009, the ban on the trading of FBL shares was lifted. Challenges, however, remained as Emma still had to remove the stigma around the company in order to restore its reputation. The first thing Emma did was to recruit professional managers to help her manage the company.

Chris Tse was the company's first professional manager. He was a reputable figure in local marketing. Educated in Canada, he had worked for several multinational corporations (MNC) in telecommunications, tourism, and banking. The two had a strong rapport. Emma thought that Chris's experience and expertise in marketing and branding would be a great asset to the company. Chris was moved by Emma's trust and passion. He decided to join FBL because he thought Emma needed him to save the company. As Chris explained:

Honestly, companies like Cartier or Tiffany don't need me, but FBL does. Emma wants to transform the company while keeping the

\footnotetext{
${ }^{9}$ In early 2010, Desmond, remaining as Deputy Chairman, resigned from the CEO position.
} 
family tradition. She doesn't want FBL to be like a traditional and typical family business. That's why she wants people like me to help remake the brand.

Emma appointed Chris as Chief Operating Officer (COO) in 2011, not just for his professional skills, but as a strategic reputational move, since FBL needed fresh faces to distance itself from the previous management and its associated scandals.

After he joined the company, Chris identified three major weaknesses of the company. The first was the absence of a clear organisational structure. Chris was surprised that the company did not have a proper organisational chart. He observed that job functions of the employees were not clear, and the chain of command was confusing. The employees confessed that they only followed the orders from the boss (referring to Fong/Jackson). Chris then introduced matrix organisation into the company. Within a year, Chris created three new departments: 'Strategic Planning', 'Group Marketing', 'Retail Marketing'. He also reformed 'Human Resources', and he incorporated the business showroom into a new department of 'Showroom and Alternative Channels'.

The second weakness he perceived was the lack of professional managers in the company. Most of the senior managers were long-serving employees whose loyalty was evidenced by their long service, which exclusively earned them senior positions in the company. Indeed, they were even called lao chenzi (people who serve the emperor for a long time). Most of these lao chenzi came from lower class families, had a low educational level, although they possessed extensive experience in the jewellery industry. Chris therefore invited his old friends and former colleagues to join FBL to head different departments including the newly established three. These newcomers shared the similar cultural outlook and professional qualification with Chris: they were all professional managers, highly educated and had worked in big corporations before. They were all initially hesitant about joining FBL, but after meeting Emma, they recalled, they were touched by her sincerity, and thought that their professional experience and expertise could help the company. Within a short period of time, FBL was staffed with a team of professional managers who were led by Chris and 'descended' from MNCs driven by salvationist aspirations to save the company.

The final problem was the corporate governance structure, in which the jiazhang made all the decisions and gave orders, and which Chris regarded as traditional and old-fashioned. Chris proposed to establish the Corporate Management Committee (CMC) in which senior managers made decisions collectively in order to align FBL with the modern corporate framework. The establishment of the CMC helped to instil the important message that, as one professional manager told us, 'a 
modern corporation is not a personal but a collective concept.' Secondly, the $\mathrm{CMC}$, following corporate managerial techniques, also started to steer the company toward a more corporate culture building by formulating the Vision, Mission, and Value (VMV) of the company. A taskforce was established to promote core corporate values to all the employees. At the same time, Chris launched a series of marketing campaigns to rebrand FBL as a modern corporation. Chris's achievements were duly recognised by Emma and Jackson, and he was promoted to Deputy CEO in 2013.

\section{Schism or Reintegration? The Replacement of Professional Managers}

The company's transformation, however, was full of tensions and conflicts. The first major set of tensions took place between the professional managers and the lao chenzi. The professional managers, consciously or unconsciously, regarded themselves as superior to the lao chenzi. They always attempted to 'teach' the lao chenzi the 'professional' way of managing business as they believed that the professional managers were there to enlighten the lao chenzi with the knowledge of modern management and thus save them from their ignorance. The lao chenzi, however, were not convinced that the professional managers were qualified to supervise them, as they were merely outsiders with no knowledge of the jewellery industries. The lao chenzi were also distrustful of the 'scientific' methods based on statistics and market research advocated by the professional managers. They tended to trust their own instincts and experience in the industry. As will be shown in a moment, the tensions pushed the lao chenzi to side with Jackson when their shaoye ('young master of the household', who was the son of their boss) tried to regain control of the company.

The sense of superiority of professional managers, rooted in the firm belief in the superiority of professional norms, inevitably clashed with Jackson's ambitions. This further gave rise to the second and most important tension: the conflict between the professional managers and Jackson himself. In September 2011, Jackson was employed as Chief Merchandising Officer while Fong was employed as an adviser under the title 'Founder'. As Wong in this special issue argues, when the father passes the jia-zu property to his sons, he is no longer seen as the 'owner' of the property, although he is still the father of his sons. Likewise, Fong became a mere symbolic figure stripped of any decision-making power after Jackson took charge of the jia-zu property and became the jiazhang, whose return disrupted the existing power relations in the company. Jackson was particularly intrigued by Chris's role and did not understand why this outsider, who was neither a jia-zu member nor family-related employee, took such an active role in the day-to-day management of the company and more importantly shared the decision-making power with him. The professional managers told us that Jackson became increasingly 
defiant of the formal organisational structure and collective decisionmaking mechanism that Chris established. He always ignored the corporate command chains and intervened directly in the operation of different departments. He also dominated the CMC meetings and did not tolerate any disagreement. The professional managers complained that the company was once again being run just like a jia, as if it were the exclusive property of the Fong family. Thus, one interviewee noted:

They [the owner-couple] enjoy bringing their kids along when they visit the retail branches. They would ask their kids to comment on the display and the manager. I don't think that's a good practice. They don't draw a line between the private sphere and the corporate sphere.

The professional managers felt that the company was becoming a one-man company again. One professional manager commented: 'Jackson just wanted you to follow his orders'. And: 'he just wanted a "yes" man.'

It was no surprise that Jackson grew impatient with the professional managers. First, the image of FBL had been greatly improved and the company was no longer in a crisis. Hence the professional managers were simply not as important to the company as they had been when first appointed. Thus, the owner-couple no longer saw themselves as dependent upon the 'fresh' faces. Second, when business was not doing well, the owner-couple started to question the value of the professional managers. Those managers were expensive and their marketing campaigns costly. And they were not seen as bringing in any notable monetary return. Finally, and most importantly, Jackson, not unlike his father, considered himself as the jiazhang of the company. He thought that his authority over his own family business should be absolute and must not be limited by the modern organisational measures or management procedures introduced by Chris. He saw the role of his employees, including the professional managers, as executing his orders, not delimiting his authority. The tension between the professional managers and the lao chenzi made the conflict more complicated. The latter chose to side with Jackson, and they only obeyed Jackson's commands. For instance, whenever the professional managers asked them to carry out their duties, the lao chenzi always expressed their reluctance and resisted the orders with the excuse that they would need to get approval from Jackson first. All of this marginalised the professional managers and caused Chris to resign in 2016. Chris's resignation further trigged a chain effect leading to the resignation of the remaining professional managers.

\section{Discussion}

The ethnographic case above illustrates aspects of professionalisation that the dominant research conducted by management scientists in family 
business studies has failed to address.

First, the case study demonstrates that the family as a social institution should be taken as a crucial factor in our study of family businesses. The 'family' here does not refer to the general culture of the family business that Hall and Nordqvist (2008) have highlighted but the specific familial ethics in particular cultural contexts. As demonstrated by the FBL's case, Chinese family firms are managed as jia. First, the jiazhang is charged with the duties of managing and running the company. He monopolises the decision-making power in every aspect of the company; he also has the absolute right, which cannot be limited by any organisational rules or procedures, to assign tasks to any of his employees. Employees are the means to implement the jiazhang's orders. Second, the status an employee enjoys and the power he gains in a Chinese family firm are determined neither by his formal position in the corporate hierarchy nor by his professional training and experience but depend on his or her relationship with the jiazhang. To cultivate a close relationship with the jiazhang, an employee must show his loyalty to the jiazhang and display his commitment to the success of the jia. One good way to do so is to stay in the company as long as possible. As we have seen from the FBL case, that is why those employees who are influential in the management of Chinese family firms, are all lao chenzi. That is also why professional managers do not automatically enjoy high status in Chinese family businesses as evidenced in what happened to Chris and his team after Jackson's return to FBL.

These factors help explain the failure of the professionalisation of FBL. The management measures Chris and his professional team introduced challenged the jiazhang's authority and limited his power. Sharing power with the professional managers signifies that employees, at least those professional managers, can no longer be considered as a means to achieve the jiazhang's ends. Rather, they are expected to be colleagues who manage the company together with the jiazhang, which is extremely rare in the Chinese family business context, as this challenges the cultural assumptions of the Chinese family that the jiazhang is the only boss who can make all decisions and give out orders and that professional managers as 'outsiders' are not allowed to share the 'ruling' power with the jiazhang. Professional managers in Chinese family businesses certainly enjoy some degree of discretionary power but they are not allowed to challenge the absolute authority of the jiazhang, let alone have a share in the decision-making power monopolised by the jiazhang.

These findings show that the culturally specific Chinese family concept shapes the way professionalisation is received in Chinese family firms. This leads to our next argument that the failure of the team of professional managers led by Chris is rooted in their lack of cultural competency to understand the culture of Chinese family businesses, 
which is largely due to the professional training and experience they have received and acquired. For the professional managers, echoing the dominant perspective of management studies, the crucial difference is not the one among family businesses, but the one between family businesses and non-family businesses with the former considered to be traditional/non-professional and the latter modern/professional. Their major mission, as they believed, was to transform the former into the latter, or at least, to align the former with the professional and managerial standard of the latter. This can best be illustrated by the salvation mentality manifested in the discourse of the professional managers. When explaining their decision to join FBL, Chris and his team members uniformly emphasised that they originally had no interest in the job offers given by Emma because of the stigma surrounding the company and because FBL was small compared to the MNCs where they previously had held positions. They pointed out that it was Emma's sincerity and her trust in the value of their professional expertise that moved them to change their mind. They were driven by a strong sense of mission that they were the only saviours who could save the struggling company and family.

Beneath the salvation mentality was a sense of superiority derived from their professional expertise and experience. The professional managers could not avoid using the professional norms derived from big (non-family) firms as their standard to make sense of and evaluate 'the way of doing things' of the FBL employees as well as the owner-couple. Behaviours that were alien to their own professional culture of expertise were classified as 'unprofessional' and 'traditional.' Seeing it as their responsibility to educate the employees and the ownermanagers in the 'modern' way of doing business, the professional managers would get upset and frustrated when the latter failed or refused to change. Their unwavering faith in the 'professional' norms also shaped their evaluations of Emma and Jackson. Jackson was seen as the major obstacle to professionalisation as he failed to see the professional managers as equal partners. He was not willing to share power with the professional managers and would defy the organisational rules set by them. To the professional managers, Jackson lacked the knowledge and appreciation of professional management. Having worked in MNCs, Emma, on the other hand, was regarded by the professional managers as being more understanding and sympathetic to their approach.

Nevertheless, they were also frustrated by Emma's failure to restrain Jackson, a failure they put down to Emma allowing her 'unprofessional' loyalties to the family to supersede her 'professional' responsibility to the company. On the other hand, the failure of the professional managers to make sense of the behaviour and logic of the owner-couple beyond the 'professional/unprofessional' framework led to the owner-couple's growing distrust of the professional managers. The fact that the managers, due to their professional expectations and norms, generally 
underestimated the significance of the 'family' ethos when it came to a Chinese family business also contributed to their inability to challenge the position of the jiazhang (Jackson).

Nevertheless, the cultural logic of the Chinese family does not strictly dictate or enable us to predict precisely how the actual course of professionalisation unfolds, as it is mediated by the interaction among various actors and the specific context that professionalisation as a social process takes place. Our use of Turner's concept of social drama to frame the professionalisation of FBL enables us to recognise that the various motivations, processes, and outcomes of the strategy of professionalisation cannot be assumed a priori. In the FBL case, the unfolding of each stage had been an unknown. The breach set in because Fong and FBL suffered a great loss from Fong's speculative activities in the local property market before the outbreak of the Asian financial crisis. It was due to this unexpected situation that Jackson replaced Fong as Chairman of the company. The prosecution of Fong and Jackson, on the other hand, was closely related to the previous financial crisis. Had Fong and Jackson not been heavily in debt, they might have refrained from embezzling money from what they saw as their company. And it was the imprisonment of Fong and Jackson that forced Emma to take charge of the company on behalf of her husband. Then, it was Emma's predicament that led to the recruitment of professional managers. And this in turn, and unintentionally, paved the way for the professionalisation of FBL. After Chris implemented a series of organisational reforms, Jackson returned and disrupted the power balance. In sum, the professionalisation of FBL was not predetermined, but was the result of specific personal and historical contingencies.

We have, then, to be cautious when generalising about this complex process and reducing it to 'ideal types.' We have to be even more cautious about asserting the casual relationships between factors. In FBL's case, for instance, it would be a mistake to simply explain the motivation or incentive for professionalisation in terms of 'the market imperative, the institutional forces, and the cultural tradition' (Chandler 1977, 1990 cited in Zhang and Ma 2009: 121). As the case reveals, professionalisation was a contingent strategy adopted by Emma to help the company overcome its specific crisis. The professional managers and the reform they implemented were desirable at that point as they could help create a fresh corporate image and dissociate FBL from the scandalous past. However, as Jackson reasserted his position in the company and the reputation of the company improved, the value of the professional managers and the professionalisation initiative decreased. Jackson has never intended to share his power with others; nor had he thought about changing the way he managed the company, even if he wanted the FBL brand to look modern and international. We will simply miss the critical point if we assume that the motivations of the owner- 
couple to professionalise the company were to increase competitiveness (e.g., Fang et al., 2012; Yildirim-Öktem and Üsdiken 2010), or to align with the modern managerial standards (e.g., Dyer 1989; Fang et al., 2012; Zhang and Ma, 2009), or to prepare for leadership succession (Dyer 1989), to name just a few of the commonly cited factors for the turn to professionalisation in the literature.

The case study also demonstrates how the process of professionalisation was shaped by the micro-politics in the company context. It shows that, in addition to the owner-managers (Emma and Jackson) and professional managers (led by Chris), the long-serving employees in the company were also important actors, whose role has largely been ignored in the previous literature of professionalisation of family businesses. The conflict between the long-serving employees and the professional managers, as demonstrated in the case, directly affected the effectiveness of professionalisation. In sum, we have to examine professionalisation as a process shaped by the contingencies of events and circumstances enacted by the agency of individual actors and their interpersonal interactions. All of this calls for a case study approach which can best capture the complexity involved in professionalisation of Chinese family businesses.

\section{Concluding Remarks}

This study has demonstrated the theoretical point that different cultural forms of family shape the process of professionalisation, and hence the 'family' should not be treated as the same cross-culturally in the study of professionalisation of family businesses. We should pay attention not just to the difference between family and non-family businesses, but the heterogeneity among the 'family' of family businesses resulting from different cultural contexts. The professionalisation process of the Chinese family business (FBL) cannot be decoupled from the specific managerial logic of Chinese family businesses, which is informed by the Chinese concept of jia. The dominant paradigm of family business studies, based on the binary view between family and business informed by Weberian rationality, fails to make sense of the operation and management of Chinese family businesses as it has taken the concept of family as abstract, ahistorical, and thus the same cross-culturally. As the assumed relationship between family and business and the assumed desirable form of professionalisation are predicated on this abstract concept of family, the dominant paradigm fails to provide tools to critically analyse professionalisation of family businesses in different cultural contexts.

Given the complexity of the contingencies of circumstances, personalities of individual actors, and micro-politics, it is also difficult to discern the complex dynamics of the social process of professionalisation through surveys and interviews alone. It is only through participant 
observations that the interaction among various actors can be discerned. The paper highlights the importance of ethnographic research to the study of professionalisation of family businesses. This methodological approach enables us to perceive professionalisation as an organic process that cannot be captured through statistics. Relying on statistics will cause us to miss the complex interplay between Chinese family businesses, micro and individual politics, and real-world market crises and recoveries.

What then are the practical implications of this paper for professional managers? The simple but often dismissed lesson is that we need to read and deal with each circumstance as a specific case instead of an exemplar of a text-book model matching to a prescribed solution. Such a reading requires overturning numerous assumptions about professionality and managerial practice. The ability to cope with the 'culture shock' is a skill that professional managers should acquire. In this sense, we are echoing Hall and Nordqvist's (2008) stress on the cultural competency of professional managers. In order to act professionally, professional managers have to be aware of their own biases and assumptions relating to the specific personalities of business families and the peculiar corporate culture of family businesses. Pride and prejudice, as shown in the case study, are the worst enemies to professional management in family businesses.

\section{References}

Berenbeim, Ronald E. 1990. "How Business Families Manage the Transition from Owner to Professional Management." Family Business Review 3(1): 69-110. https://doi.org/10.1111/j.1741-6248.1990.00069.x Chittoor, Raveendra, and Ranjan Das. 2007. "Professionalization of Management and Succession Performance - A Vital Linkage." Family Business Review 20(1): 65-79. https://doi.org/10.1111/j.1741$\underline{6248.2007 .00084 . \mathrm{X}}$

Dekker, Julie C., Nadine Lybaert, Tensie Steijvers, Benoît Depaire, and Roger Mercken. 2013. "Family Firm Types Based on the Professionalization Construct: Exploratory Research." Family Business Review 26(1): 81-99. https://doi.org/10.1177/0894486512445614

Dekker, Julie C., Nadine Lybaert, Tensie Steijvers, and Benoît Depaire. 2015. "The Effect of Family Business Professionalization as a Multidimensional Construct on Firm Performance." Journal of Small Business Management 53(2): 516-538. https://doi.org/10.1111/jsbm.12082

Dyer, W.Gibb. 1986. Cultural Change in Family Firms: Anticipating and 
Managing Business and Family Transitions, San Francisco, CA: Jossey-Bass.

Dyer, W. Gibb. 1989. "Integrating Professional Management into a Family Owned Business." Family Business Review 2 (3): 221-235.

https://doi.org/10.1111/j.1741-6248.1989.00221.x

Fang, Hanqing, Esra Memili, James J. Chrisman, and Dianne H.B. Welsh. 2012. "Family Firms' Professionalization: Institutional Theory and Resource-Based View Perspectives." Small Business Institute Journal 8 (2): 12-34.

Giovannoni, Elena, Maria Pia Maraghini, and Angelo Riccaboni. 2011. "Transmitting Knowledge Across Generations: The Role of Management Accounting Practices." Family Business Review 24(2): 126-150. https://doi.org/10.1177/0894486511406722

Hall, Annika and Mattias Nordqvist. 2008. "Professional Management in Family Businesses: Toward an Extended Understanding." Family Business Review 21(1): 51-69. https://doi.org/10.1111/j.1741-6248.2007.00109.x Johannisson, Bengt, and Morten Huse. 2000. "Recruiting outside board members in the small family business: an ideological challenge." Entrepreneurship \& Regional Development 12: 353-378. https://doi.org/10.1080/08985620050177958

Lin, Shu-hui, and Shing-yang Hu. 2007. "A Family Member or Professional Management? The Choice of a CEO and Its Impact on Performance." Corporate Governance 15(6): 1348-1362. https://doi.org/10.1111/j.1467-8683.2007.00650.x

Polat, Gülçin. 2020. "Advancing the multidimensional approach to family business professionalization." Journal of Family Business Management, ahead-of-print. https://doi.org/10.1108/JFBM-03-2020-0020

Salvato, Carlo, Alessandro Minichilli and Raffaella Piccarreta. 2012. "Faster Route to the CEO Suite: Nepotism or Managerial Proficiency?" Family Business Review 25(2): 206-224. https://doi.org/10.1177/0894486511427559

Songini, Lucrezia. 2006. "The professionalization of family firms: theory and practice." In Handbook of Research on Family Business, edited by Panikkos Zata Poutziouris, Kosmas X. Smyrnios and Sabine B. Klein, 269297. Cheltenham; Northampton, MA: Edward Elgar.

Stewart, Alex, and Michael A. Hitt. 2012. "Why Can't a Family Business Be More Like a Nonfamily Business? Modes of Professionalization in Family Firms." Family Business Review 25 (1): 58-86. https://doi.org/10.1177/0894486511421665

Tsui-Auch, Lai Si. 2004. "The Professionally Managed Family-ruled Enterprise: Ethnic Chinese Business in Singapore." Journal of Management Studies 41 (4): 693-721. https://doi.org/10.1111/j.1467$\underline{6486.2004 .00450 . x}$ 
Turner, Victor. 1987 [1974]. Dramas, Fields and Metaphors: Symbolic Action in Human Society. Ithaca, NY: Cornell Univesity Press.

Wong, Heung Wah, and Karin Ling-Fung Chau. 2020a. Tradition and Transformation in a Chinese Family Business. London: Routledge. https://doi.org/10.4324/9781315690612

Wong, Heung Wah, and Karin Ling-Fung Chau. 2020b. "Several Things that We Know about Creativity" in Creative Context: Creativity and Innovation in the Media and Cultural Industries, edited by Nissim Otmazgin and Eyal Ben-Ari. Singapore: Springer, 121-141.

Yanagisako, Sylvia Junko. 2010. Producing culture and capital: family firms in Italy. Princeton: Princeton University Press.

Yildirim-Öktem, Özlem, and Behlül Üsdiken. 2010. "Contingencies versus External Pressure: Professionalization in Boards of Firms Affiliated to Family Business Groups in Late-Industrializing Countries." British Journal of Management 21: 115-130. https://doi.org/10.1111/i.14678551.2009.00663.x

Zhang, Jianjun, and Hao Ma. 2009. "Adoption of professional management in Chinese family business: A multilevel analysis of impetuses and impediments." Asia Pacific Journal of Management 26: 119-139 https://doi.org/10.1007/s10490-008-9099-y

Karin Ling-Fung Chau is a PhD candidate at the Department of Culture, Media and Creative Industries, King's College London. She is conducting adoctoral research on the animation industry in China. She is the co-author of Tradition and Transformation in a Chinese Family Business (with Heung Wah Wong) (Routledge 2020). Her research interests include cultural politics in Chinese societies, creative industries in China and Chinese entrepreneurship.

Heung Wah Wong currently is the Acting Head of the School of Modern Languages and Cultures at The University of Hong Kong. Wong is also the founder of Global Creative Industries program at The University of Hong Kong. His research interest lies in business anthropology, globalization of Japanese popular culture, and Chinese kinship. His major publications include Japanese Bosses, Chinese Workers: Power and Control in a Megastore in Hong Kong (Hawaii University Press and Curzon Press 1999), Japanese Adult Videos in Taiwan (co-authored with Hoi-yan Yau, Routledge 2014), The Japanese Adult Video Industry (coauthored with Hoi-yan Yau, Routledge 2017), Tradition and Transformation in a Chinese Family Business (co-authored with Karin Ling-fung Chau, Routledge 2020), and various journal articles. 